STUDI

FRANCESI

\section{Studi Francesi}

Rivista quadrimestrale fondata da Franco Simone

175 (LIX | I) | 2015

Varia

\title{
Aa. Vv., Commenter et philosopher à la Renaissance. Tradition universitaire, tradition humaniste, sous la direction de Laurence Boulègue
}

\section{Maurizio Busca}

\section{(2) OpenEdition}

\section{Journals}

\section{Edizione digitale}

URL: http://journals.openedition.org/studifrancesi/386

DOI: $10.4000 /$ studifrancesi.386

ISSN: 2421-5856

\section{Editore}

Rosenberg \& Sellier

\section{Edizione cartacea}

Data di pubblicazione: 1 aprile 2015

Paginazione: 133

ISSN: 0039-2944

\section{Notizia bibliografica digitale}

Maurizio Busca, «Aa. Vv., Commenter et philosopher à la Renaissance. Tradition universitaire, tradition humaniste, sous la direction de Laurence Boulègue », Studi Francesi [Online], 175 (LIX | I) | 2015, online dal 01 avril 2015, consultato il 18 septembre 2020. URL : http://journals.openedition.org/ studifrancesi/386 ; DOI : https://doi.org/10.4000/studifrancesi.386

Questo documento è stato generato automaticamente il 18 settembre 2020.

\section{c) $(9 \ominus$}

Studi Francesi è distribuita con Licenza Creative Commons Attribuzione - Non commerciale - Non opere derivate 4.0 Internazionale. 


\title{
Aa. Vv., Commenter et philosopher à la Renaissance. Tradition universitaire, tradition humaniste, sous la direction de Laurence Boulègue
}

\author{
Maurizio Busca
}

\section{NOTIZIA}

Aa. Vv., Commenter et philosopher à la Renaissance. Tradition universitaire, tradition humaniste, sous la direction de Laurence BoulÈGuE, Villeneuve d'Ascq, Presses Universitaires du Septentrion, 2014 («Cahiers de philologie», 31), pp. 312.

1 Il commento a testi filosofici è, nel Quattrocento, una delle pratiche più diffuse nelle università, e si fonda su metodi e schemi ereditati dalla Scolastica. Gli intellettuali umanisti che attraverso il lavoro di edizione, traduzione e commento dei testi antichi rinnovano lo studio della filosofia classica non rompono radicalmente con questa tradizione, ma ne ereditano alcuni aspetti; parallelamente, nelle università vengono accolti nuovi strumenti e metodi di studio, e si guarda a opere che prima di allora non rientravano nel corpus tradizionale: «la dialectique entre les deux courants, scolastique et humaniste, donne lieu aussi à une refonte plus profonde du commentaire scolastique» (L. BOULÈGUE). Il presente volume intende rilevare non soltanto la permeabilità reciproca dei due courants qui evocati (parti 1 e 2), ma anche l'apertura del commento filosofico umanista agli apporti di altre discipline - in primo luogo la filologia - e alla sua applicazione in ambiti che tra Quattro e Cinquecento sono al centro di un rinnovato interesse: oggetto di commento non sono più unicamente $i$ testi filosofici, ma anche i trattati di architettura, poesia, drammaturgia, musica (parte 3). Luogo di attualizzazione del pensiero antico e di elaborazione di un pensiero individuale, il commento filosofico si offre quale luogo privilegiato per lo studio della 
nascita del pensiero umanista, e ne rileva i debiti, più cospicui di quanto non si creda, nei confronti della tradizione scolastica.

2 Il volume si articola in tre parti e riunisce i contributi seguenti. «Première partie» («Philosophie humaniste et commentaire universitaire: permanences et mutations»): Carlos LÉVY, Quelques remarques introductives sur la genèse du commentaire philosophique, pp. 19-27; Susanna GAMBINO-LONGO, La question de la mortalité de l'âme dans les commentaires humanistes de Lucrèce de G.B. Pio et D. Lambin, pp. 29-46; Thierry GONTIER, Pulex contra elephantum: Pomponazzi et Thomas, lecteurs du "De anima" d'Aristote, pp. 47-60; Violaine GIACOMOTTO-CHARRA, Commenter Aristote à la fin du XVI eiècle: L'exemple du "De naturalibus rebus" de Giacomo Zabarella, pp. 61-75; Demmy VERBEKE, Entre philosophie et philologie: Le "Vigilia in Somnium Scipionis" (1520) de Juan Luis Vivès, pp. 77-87; Laurence BOULÈGUE, Philosophie humaniste et commentaires universitaires. La question de la contemplation dans les "Opuscula moralia" d'Agostino Nifo, pp. 89-103; Jan PAPY, Comment lire Sénèque? Les commentaires des "Questions Naturelles" de Libertus Fromondus, pp. 105-119. «Deuxième partie» («La redécouverte de Platon et l'exégèse néoplatonicienne»): Pierre LAURENS, "Flos commentariorum". La place du "Commentaire sur le Banquet" dans le corpus des "Commentaria in Platonem", pp. 123-134; Michael J.B. ALLEN, Plato's "Gorgias", Ficino and the Poets, pp. 135-147; Alain LERNOULD, De la Nature Universelle chez Proclus (In Timaeum I, 9.25-12.25) et chez Ficin (commentaire sur le "Sophiste" ch. 45), pp. 149-161; Stéphane TOUSSAINT, Francesco Cattani Da Diacceto commentateur du "Banquet". Note néoplatonicienne, pp. 163-170; Pierre MAGNARD, Bovelles lecteur de Denys, pp. 171-176. "Troisième partie» («L'herméneutique philosophique et les artes»): Pierre CAYE, Alberti "traducteur" du "De architectura" de Vitruve, pp. 179-188; Florence MALHOMME, La musique dans le commentaire au "De Architectura" de C. Cesariano (1521), pp. 189-207; John NASSICHUK, Entre traduction et commentaire. La paraphrase du livre $\lambda$ de la "Métaphysique" d'Aristote par Marcantonio Flaminio, pp. 209-224; Virginie LEROUX, Commentaire et cadrage du sens: l'"error" tragique selon Francesco Robortello et Martin Antoine Del Rio, pp. 225-238; Hélène CASANOVA-ROBIN, Le mythe de Diane et Actéon dans les "Fureurs héroïques" de Giordano Bruno (1585): du commentaire d'un poème ovidien à l'élaboration d'un paradigme philosophique et esthétique, pp. 239-259; Philip FORD, Les commentaires philosophiques dans le "Mythologicum" de Jean Dorat, pp. 261-271. 